\title{
O ESCRITOR E A CIDADE: QUE BAHIA É ESSA QUE GIL E CAETANO NÃO CANTARAM?
}

\section{THE WRITER AND THE CITY: WHAT IS IT THAT BAHIA CAETANO AND GIL DID NOT SING?}

\author{
Maria Cleci Venturini* \\ Níncia Cecilia Ribas Borges Teixeira ${ }^{* *}$
}

RESUMO: O artigo analisa o texto "A Bahia que Caetano e Gil não cantaram" inserido no livro Literatura Marginal, organizado por Ferréz. O estudo se embasa em uma perspectiva discursivo-literária evidenciando que o contexto histórico-social é parte constitutiva do sentido e a formação ideológica governa a formação discursiva. A escolha se deveu ao fato de que o texto apresenta um discurso marcado por um eu-lírico de um outro contexto histórico-geográfico, condicionado por uma formação ideológica que, diante de seu objeto lírico (Bahia), integra-se a ele. O que nos move e impulsiona à reflexão em torno do espaço urbano é a possibilidade de aliar, de um lado, o que é da ordem do real e significa pela institucionalização que rege e direciona a vida da formação social e dos sujeitos que a estrutura e, de outro, o ficcional, que vem de um outro lugar. Esse outro lugar não se filia ao real, nem à literatura canônica, mas existe, fazendo sentido. Trata-se da Literatura Marginal, em que os talentos significam o seu lugar como o "de escrita periférica", isto é, daqueles que são "talentos", mas nem sempre são reconhecidos.

PALAVRAS-CHAVE: cidade, Bahia, discurso, literatura.

ABSTRACT: The paper analyzes the text "Bahia Caetano and Gil who did not sing" inserted in the book Marginal Literature, organized by Ferréz. The study was grounded in a perspective discursive and literary evidence that the socio-historical context is constitutive of meaning and ideological formation governs to discursive formation.

\footnotetext{
* Universidade Estadual do Centro-Oeste (Unicentro), Guarapuava/PR. Doutora em Estudos Linguísticos pela Universidade Federal de Santa Maria (UFSM). Email: mariacleciventurini@hotmail.com.

** Universidade Estadual do Centro-Oeste (Unicentro), Guarapuava/PR. Coordenadora do Programa de Mestrado em Letras. Pós-Doutora pela Universidade Federal do Rio de Janeiro (UFRJ). Doutora em Letras pela Universidade Estadual Paulista Júlio de Mesquita Filho (Unesp). Email: nincia@unicentro.br.
} 
The choice was due the fact that the text presents a discourse marked by a self-lyrical in another historic-geographic context, conditioned by an ideological formation that, in light of its object lyric (Bahia), is part of it. What drives us and pushes for reflection on the urban space is the possibility of allying on the one hand, what is the order of the real and institutionalization means that rules and directs the life of a social formation of subjects and that the structure and other fiction, that comes from another place. This other place does not belong to actual, or the canonical literature, but it exists and makes sense. This is Marginal Literature, in which the talents mean its place as the "peripheral writing", i.e. those who are "talented", but are not always recognized.

KEYWORDS: city, Bahia, speech, literature. 


\section{O ESCRITOR E A CIDADE: QUE BAHIA É ESSA QUE GIL E CAETANO NÃO CANTARAM?}

\section{Introdução}

"Compreender, eu diria, é saber que o sentido pode ser outro" (Eni Orlandi).

A temática Literatura e Espaço Urbano tem despertado pesquisas em diversos campos do saber, de modo que historiadores, arquitetos, sociólogos, antropólogos e estudiosos da língua e da literatura têm enfrentado o desafio de inscrever a cidade como espaço de concentração de linguagens, que compõe o discurso da modernidade. Na literatura, a experiência urbana e a cena escrita estão, ambas, inseridas no mundo do possível, do significado, mas também no mundo em que nem tudo é dito, muito é esquecido, mas, contraditoriamente e independentemente de "vontades" e de "desejos", a cidade sempre significa como a imaginada/idealizada ou como a marginalizada, violenta e feia que nenhum poeta quer cantar/ amar/vislumbrar...

Nessa perspectiva, indagar sobre as representações da cidade na cena escrita construída pela literatura é, basicamente, ler textos que leem a cidade, considerando não só a paisagem urbana, os dados culturais mais específicos, os costumes, os tipos humanos, mas também a cartografia simbólica, em que se cruzam o imaginário, o ficcional, a história, a memória da cidade e 
a cidade da memória. A relação Literatura e Experiência Urbana tornouse mais visível na modernidade, quando a cidade transformada pela Revolução Industrial se apresenta como um fenômeno novo dimensionado na metrópole. Essa cidade da multidão, que tem a rua como traço forte de sua cultura, passa a ser não só cenário, mas também a grande personagem de muitas narrativas, ou a presença incorporada em muitos poemas. Assim é Paris para Baudelaire; Londres para Dickens; Buenos Aires para Borges; Lisboa para Eça de Queirós; Rio de Janeiro para Machado de Assis; e Porto Alegre para Pesavento.

Considerar a cidade como discurso é tomá-la como forma diferenciada da linguagem. A cidade escrita é, então, resultado da leitura, construção do sujeito que a lê, que a pensa como condensação simbólico-material, como espaço discursivo, em que a cidade é a materialidade a ser lida, significada. A escritura da cidade e a leitura desse texto constituído nela/por ela se dá pela impossibilidade do todo, dos sentidos fechados e homogêneos. Para ler esse texto estruturado pelo espaço urbano é necessário engendrar uma forma de dar sentido a essa pseudorrealidade, sempre móvel e movente, possibilitando um jogo aberto à complexidade.

O que nos move e impulsiona à reflexão em torno do espaço urbano é a possibilidade de aliar, de um lado, o que é da ordem do real e significa pela institucionalização que rege e direciona a vida da formação social e dos sujeitos que a estruturam e, de outro, o ficcional, que vem de um outro lugar. Esse outro lugar não se filia ao real, nem à literatura canônica, mas existe, fazendo sentido. Trata-se da Literatura Marginal, em que os talentos significam o seu lugar como o "de escrita periférica", isto é, daqueles que são "talentos", mas nem sempre são reconhecidos.

Para significar esse outro espaço da cidade, analisamos o texto "A Bahia que Caetano e Gil não cantaram", poema escrito por "Gato Preto", inserido na obra Literatura Marginal, organizada por Férrez (Reginaldo Ferreira da Silva). Os sentidos do que seja este livro, que se autoidentifica de literatura marginal, estão impressos na orelha esquerda do livro. Nesse espaço está escrito/sentenciado que "a voz literária predominante é treinada na universidade, geralmente equipada de livros em casas de gente de classe média e alta, e costuma reverberar apenas entre esses mesmos nichos". Disso se pode ler/interpretar/compreender, nos sentidos que Orlandi (2004) dá à leitura/ interpretação, que há outra voz literária que ressoa e esta voz é a dos sujeitos-poetas da periferia, os que estão fora da urbe institucionalizada. 
O autor do livro e também criador, em 2000, da revista Literatura Marginal, diz, mas nem precisaria dizer, que a criação da revista tem por objetivo modificar o cenário literário, fazendo circular também o que fica de "fora". Trata-se do ressoar de voz de "quem não tem voz". O grupo congrega mais trinta autores brasileiros e o elo que os liga é o "estigma da marginalização social com necessidade e capacidade de expressão". Após cinco anos de circulação, a revista vira livro, no qual estão reunidos vinte e seis textos de onze autores, que vivem à margem da literatura e da sociedade, mas (também está dito na orelha do livro) "com fôlego vivo para romper o gueto e a exclusão". Diante desse contexto, propomos aceitar o desafio de Gato Preto e analisar, na perspectiva discursiva, o seu trabalho. A relevância do texto está na promessa, talvez ameaça, de dar visibilidade e destaque à "Bahia que Gil e Caetano não cantaram".

O corpus selecionado é da ordem do inusitado, para não dizer do estranho, do diferente. Entramos, então, nessa ordem do discurso e nos "arriscamos" a trabalhar com conceitos constituídos na $\mathrm{AD}$ em torno do espaço urbano. O espaço que buscamos, entretanto, vem de um lugar bem marcado: a periferia. A proposta do autor é mostrar uma outra cidade, desnudando a Bahia cantada em versos e em prosa por Caetano e Gil, mas não só por eles, como também por Jorge Amado e outros. Este último, apesar de mostrar um outro lado da cidade, o fez homenageando, de certa forma, as prostitutas, os meninos de rua, os boêmios. Do nosso lugar de analistas, nos lançamos sobre esse objeto e o inscrevemos na ordem do discursivo e nele/ por ele buscamos articular um imaginário urbano vindo da literatura marginal por meio de conceitos teóricos da Análise de Discurso, de orientação francesa, conforme sinalizamos anteriormente.

Ao nos inscrevermos nesse espaço movente, localizado no entremeio entre o real e o ficcional, passamos a transitar pelos espaços que a ficção apaga e pelos que ela dá visibilidade, em um movimento contraditório, marcado por equívocos, faltas e falhas, bem ao gosto do discursivo. Entendemos, motivados por esse objeto, que tanto no espaço urbano designado de "real" quanto no "inventado" ressoam "outras cidades", assim como ressoaram em Pesavento (2002), quando fala de cidades imaginárias, em que ela, enquanto sujeito-autor, ouviu "os ecos do sul", falando de Porto Alegre, e vislumbrou o duplo por meio da cidade do espelho, o Rio de Janeiro, sustentando (PESAVENTO, 2002, p. 61) a possibilidade de coexistência de duas cidades: a que se pretende real e a constituída/instituída pela ficção. A essas duas 
acrescentamos a cidade que não é real, nem da ficção, ou seja, a cidade periférica, às margens de uma sociedade marcada pela institucionalização e pelos jogos de poder. Isto posto, nos aventuramos por essa cidade.

\section{Espaço urbano na perspectiva discursivo-literária}

A cultura da modernidade é, eminentemente, urbana e comporta duas dimensões indissociáveis: por um lado, a cidade é o sítio da ação social renovadora, da transformação capitalista do mundo e, por outro, torna-se, ela própria, o tema e o sujeito das manifestações culturais e artísticas. Dessa forma, é na correlação modernidade-cidade que encontramos a passagem da ideia da urbe como local onde as coisas acontecem. A metrópole é a forma mais específica da realização da vida moderna.

A produção literária é um fenômeno social à medida que resulta de convicções, crenças, códigos e costumes sociais. Enquanto tal, exprime a sociedade, não integralmente, mas modificando-a e, até mesmo, negando-a. Se a literatura emerge de uma determinada realidade histórica, isso não implica que deva ser o seu registro fiel, apresentando dela uma imagem em que a própria sociedade, muitas vezes, recusa-se a reconhecer. Não é intenção do texto literário provar que os atos narrados tenham acontecido concretamente, mas a narrativa comporta em si uma explicação do real e traduz uma sensibilidade diante do mundo, recuperada pelo autor. Para Mannheim (1982, p. 90): "Todas as idéias, sejam elas utopias ou ideologias, têm de ser vistas em sua vinculação social e não à luz de critérios imanentes de veracidade".

Se a cidade é um pedaço do mundo, suas imagens são enigmas sobre as quais, ao tentarmos decifrá-las, lançamos nossas interpretações subjetivas. Walter Benjamim, ao perambular pelas ruas de Moscou, imagina suas imagens sobre aquelas que o olho vê; ao projetar suas fantasias e esperanças, escreveu um precioso documento pessoal sobre essa cidade, em Diário de Moscou. As imagens de uma cidade não se resumem ao que é visto na sua objetividade, livre das desordens do desejo e do devaneio de um sonhador; são todas as fotografias por ele imaginadas. A cidade enquanto paisagem tem a imaginação como faculdade fundamental de sua interpretação.

$\mathrm{Na}$ leitura da cidade, precisa-se ter cuidado para não confundir as imagens do mundo real e as que são inventadas, motivadas pelo desejo de ver e de encerrar em um conceito ou em um repertório o objeto observado.

É preciso dizer que por trás das imagens oferecidas à objetividade do olhar existem outras que se mostram em doses homeopáticas, que são 
aquelas imagens instantâneas, surgidas da relação direta do sujeito com a cidade.

Intrinsecamente ligado à modernidade, o universo urbano passa por transformações profundas e diversificadas que lhe alteram o perfil e a própria vida de seus habitantes: experiências e sonhos, necessidades e temores. Tudo ambiguamente novo e em permanente mudança, a alterar não apenas o cenário, mas também a própria construção do imaginário da cidade.

Os novos espaços urbanos tornam-se lugares e objetos de uma composição visual que articula e é articulada por novas experiências objetivas e subjetivas. Divertimento e alienação, prazer e medo, mobilidade e confinamento, expansão e fragmentação passaram a constituir as principais características da cidade metrópole do século XX.

No espaço urbano, de acordo com Orlandi (2004), ancora a coexistência do duplo, pelo qual coexistem dois significados: o espaço urbano significado pelos sujeitos-cidadãos, e que os significa, e a "outra cidade", que povoa o imaginário desses sujeitos, constituídos, segundo Orlandi (2004, p. 186), no confronto entre o simbólico e o político, articulados de forma particular. Ainda segundo a mesma autora, pensar a cidade, enquanto espaço urbano, não limita o analista à descrição da organização da discursividade dela, mas o impulsiona a compreender a ordem desse discurso, isto é, a buscar saber como a cidade se significa, como ela se diz, é dita e, pela linguagem, se espacializa.

Por ser do ponto de vista discursivo, “[...] um espaço simbólico particular que tem sua materialidade e que produz sua própria forma de significar" (ORLANDI, 2004, p. 186), a cidade se constitui como o lugar em que se articulam o simbólico e o político, perpassados por gestos de interpretação particulares e específicos, resultantes de dois domínios: o da ordem e o da constituição. A ordem articula o simbólico ao real e a organização, o empírico ao imaginário.

Para Orlandi, ela é "[...] o acontecimento social por excelência na atualidade" (2004, p. 21). Alia-se a um real, ao que é e ao que deveria ser de acordo com a ordem estabelecida, mas que em sua organização empírica não o é. Liga-se o empírico a algo que não é pensado para assim ser, mas para ser, para existir no imaginário, nas projeções que cada sujeito-cidadão, perpassado pela ideologia, realiza e constitui como sujeito afetado pela ideologia e atravessado pelo inconsciente. 


\section{Representações urbanas: o escritor da cidade}

Não vês que o olho abraça a beleza do mundo inteiro? Quem acreditaria que um espaço tão reduzido seria capaz de absorver as imagens do universo?

(Leonardo da Vinci).

O que seria, a rigor, a identidade urbana, senão algo que percorre os caminhos do sensível e do imaginário? E, nesta medida, a literatura tem se revelado o veículo por excelência para captar sensações e fornecer imagens da sociedade, por vezes, não admitidas por esta ou que não são perceptíveis nas tradicionais fontes documentais utilizadas pelo historiador. As representações literárias registram, em suas particularidades formais, em seus modos e estilos, os símbolos da pluralidade, os sinais que diferenciam mundos histórico-sociais diferentes. Como imagens, essas representações literárias revelam uma relação de contiguidade com a realidade.

Para Chartier (1990, p. 25), "Práticas e representações pressupõem usos e funções diferenciais dos mesmos objetos, leituras plurais de indivíduos, grupos e da sociedade sobre os mesmos fenômenos e os variados argumentos possíveis". Para ele, o conceito de representação permite designar realidades essenciais: em primeiro lugar, as representações coletivas que incorporam nos indivíduos as divisões de mundo (as classificações) e que organizam os esquemas de percepção e avaliação, a partir dos quais se orientam o julgamento e a ação. A seguir, também, designam-se as formas de exibição do ser social ou do poder político, tais como se dão a ver pela imagem, pelo rito, pela estilização da vida, por sinais, pela arte.

As representações urbanas não são mera conversão de um fato urbano a uma forma representativa dele, elas devem ser entendidas como componentes da prática social. A identidade urbana lida com aquelas dimensões enunciadas por Rama da cidade real e da cidade ideal. Segundo Rama:

Tal postura implica entender a cidade como uma articulação de signos que compõe uma identidade social e é culturalmente construída. A cidade pensada e formulada no imaginário é o reflexo não mimético de uma cidade física, com seu traçado urbano e sua complexidade social, que se interroga no espelho (1985, p.18). 
Assim, as imagens reapresentam ou apresentam de novo (na modalidade do tempo), ou no lugar de (na modalidade do espaço), as situações de interação dos indivíduos com as relações que as articulam às determinações longínquas, às vezes invisíveis, que tornam possível sua realização. Recuperar as imagens produzidas pela literatura, buscar traços e gestos esquecidos, marcas perdidas, significa reconstituir as representações dessa sociedade. Como imagens de uma época, atravessam os textos, transformando-os; atravessados por elas, os textos se transformam, reconstituindo contrastes e significações.

Por meio da representação, fundam-se os paradigmas do espaço, do tempo, da compreensão da matéria, do signo, da representação, das linguagens, do discurso e do conhecimento. Ela é uma forma de apresentar o objeto da materialidade crua do mundo, para transversá-lo pela trama do signo, da palavra, e, assim, outra vez apresentá-lo. A representação é da ordem do sígnico ou do simbólico, do real possível e do imaginário.

A representação envolve uma relação ambígua entre ausência e presença. No caso, ela é a presentificação de um ausente, que é dada a ver uma imagem mental ou visual que, por sua vez, suporta uma imagem discursiva. A representação, pois, enuncia um outro distante no espaço e no tempo, estabelecendo uma relação de correspondência entre ser ausente e ser presente que se distancia do mimetismo puro e simples, ou seja, as representações do mundo social não são o reflexo do real, nem a ele se opõem de forma antitética, em uma contraposição vulgar entre imaginário e realidade concreta.

Há, no ato de tornar presente, a construção de um sentido ou de uma cadeia de significações que permite a identificação. Representar, portanto, tem o caráter de anunciar, "pôr-se no lugar de", estabelecendo uma semelhança que permita a identificação e o reconhecimento do representante com o representado. Por outro lado, as representações do mundo social não se medem por critérios de veracidade ou autenticidade, e, sim, pela capacidade de mobilização que proporcionam ou pela credibilidade que oferecem.

O espaço urbano não é somente o local em que ocasionalmente nos encontramos, mas a imagem mental que cada um faz do espaço da vida e que, dado o mesmo fundo de experiência, é a mesma para todos os indivíduos do mesmo grupo, com exceção de pequenas diferenças específicas: "O meio social que amolda o artista não só se inscreve na sua obra como também se insinua na inspiração que brota nele sob forma exterior. Esta forma, de certa maneira, ele também pode inventar" (BASTIDE, 1971, p. 73). 
Logo, pode-se admitir que as imagens da cidade, consideradas aqui como as formas que servirão de suporte à representação, que emanam da obra de arte em geral, e da literatura em particular, reduzem-se a uma espécie de presença do todo circundante. E o escritor, por conseguinte, será aquele que executará o seu fazer, utilizando-se da língua e da linguagem, como literatura, remetendo sua cosmovisão para realidades ficcional e discursivo-literárias, que se articulam pela realidade vivenciada.

Pode-se dizer que o discurso literário comporta, também, a preocupação com a verossimilhança. A ficção não seria, pois, o avesso do real, mas uma outra forma de captá-lo, em que os limites de criação e fantasia são mais amplos que aqueles permitidos ao historiador.

É este, ao que parece, o verdadeiro papel social da literatura: agir por vias sinuosas. O discurso ficcional seria uma quase história, não precisa comprovar nada ou se submeter a testes, mas guarda preocupações com certa refiguração temporal, partilhada com a história.

Se o artista se deixa levar pela imaginação a uma dupla realidade ou se, como ocorre na contemporaneidade, evidencia a realidade de modo ideal, ou hostil, ou até mesmo fantástico, é porque, de fato, essa realidade se lhe apresenta dessa forma. Se a obra de arte literária espelha o mundo, se este mundo manifesta-se adverso do ideal, agressivo, descomposto, fracionado ou corrompido, ela apenas cumpre o seu papel de denunciar a situação em vigor e, quiçá indiretamente, poderá contribuir para uma possível transformação das circunstâncias.

A literatura que representa esse processo trabalha o binômio de dupla implicação - modernidade e experiência urbana - e gera o cânone que se institucionalizou enquanto tradição seletiva, com a autoridade que excluía outros modos históricos de representar a realidade citadina. Se a cidade dos centros hegemônicos era o modelo, aquelas situadas fora desse eixo deveriam copiá-la como símbolo da civilização e da modernidade, na tentativa de apagar as diferenças.

\section{A desconstrução da Bahia: o esfacelamento da cidade}

Nas narrativas urbanas, as cidades eram as esfinges do moderno. O herói, muitas vezes provindo de modorrento recanto rural, chegava à metrópole na ânsia da conquista. Sedutora, a cidade piscava suas luzes espraiando-se no desafio: "decifra-me ou devoro-te". E o herói ou a decifrava, galgando posições sociais, construindo edifícios, inventando modas, máquinas ou 
revoluções, ou perdia-se na massa dos desiludidos, que perambulam pela rua do anonimato.

$O$ desafio de interpretar as engrenagens da cidade moderna inaugurou, ao longo dos séculos XIX e XX, fronteiras disciplinares. Nas narrativas e no cinema das primeiras décadas do século XX, a cidade despontava como o cenário do moderno, o local onde a vanguarda artística, as invenções técnicas e novos estilos de vida eram ensaiados.

Hoje, as cidades são cenários cada vez mais complexos de negociações econômicas, sociais e culturais. Sobretudo, os meios de comunicação e de transporte, além da confluência entre zonas periféricas, fazem com que as metrópoles contemporâneas já não tenham uma nítida demarcação territorial.

Ler a cidade é tentar entender essa rede intrincada, rastreando ideias, metáforas, símbolos para, a partir deles, construir uma espécie de mapeamento, um outro tecido - uma outra representação. Ler a cidade é, ainda, perceber que o intrincado da rede é, ele mesmo, o resultado de uma concentração de linguagens. Decifrar linguagens é, pois, a tarefa do leitor de cidades que, em sua particular leitura, promove uma espécie de atualização de traços formadores dessa tessitura de signos que a cidade contém. Ao promover a atualização, o leitor constrói, pela representação, a sua cidade, pois está claro que qualquer cidade é um pouco construída por aqueles que a leem.

Cada leitor lê a cidade em um processo que também atualiza os seus códigos de decifração. É com eles que se leem os recortes e os fragmentos daquilo que conseguiu perceber na cidade. A partir daí, cada leitor vai construir/escrever uma espécie de mapa particular, a sua representação da cidade na cidade. O desejo de quem olha é o que dá forma à cidade.

A narrativa literária estabelece uma transcendência sobre o real, ela constrói seu discurso pelos caminhos do imaginário e os fatos chegam até o leitor como representação de algo, problematizando a realidade histórica. A realidade histórica é mero instrumento, matéria-prima sobre a qual $o$ artista recria a realidade. $\mathrm{O}$ escritor exterioriza seu ser no mundo real, ele também o interioriza como realidade objetiva. Existe uma profunda dinâmica entre indivíduo e sociedade feita de interações, deslocamentos e modificações.

O sujeito-autor do poema "A Bahia que Gil e Caetano não cantaram" inicia a sua fala interpelando interlocutores, designando-os de Iludidos: 
"Iludidos, vê só quem chegou, pode me chamar de Gato Preto, ${ }^{1}$ o invasor" (GATO PRETO, 2005, p. 51). Nessa/por essa designação ressoam sujeitos que se deixam conquistar pela Bahia em que "[...] toda menina tem defeito, mas é a mais bonita”, segundo Gilberto Gil. A Bahia, para Caetano, é paradisíaca. A marcação geográfico-simbólica feita por Gato Preto na obra "A Bahia que Gil e Caetano não cantaram" utiliza o espaço como metáfora para conotar o conflito entre diferentes imaginários urbanos. $\mathrm{O}$ autor nos mostra, nessa materialidade discursiva, o começo de certo dilaceramento do espírito coletivo da cidade, através da fragmentação e do esfacelamento das imagens da cidade: "Bahia do descaso, descamisados, desabrigados" (GATO PRETO, 2005, p. 52).

$A$ visibilidade dada à Bahia de sujeitos idealizados e vencedores apaga o outro lado da cidade baiana. É por isso que, diante de sujeitos "iludidos", o "invasor" - o Gato Preto - chega para desconstruir a cidade perfeita. Como invasor ou porque se diz invasor, ele inicia a descrição da cidade, cantada em versos e descrita em prosa como maravilhosa, pelo lado da violência, marcando-a com o estigma que faz dela um espaço de desigualdade, de morte e de solidão: "Vem conhecer a Bahia, sou um guia diferente, mostro a verdadeira cara da nossa gente, vai ver que não é só carnaval, praia e acarajé. Bahia de Todos os Santos? Besteira" (GATO PRETO, 2005, p.53).

A Bahia de Gato Preto é habitada por trabalhadores: "Falo do pescador que sai às três da manhã" (GATO PRETO, 2005, p. 52), rompendo com o estereótipo do baiano folgado, o autor retrata outra face da cidade, confirmando o que afirma Renato Gomes:

Pela nova geografia urbana, a cidade não é mais o território delimitado, percebido como próprio dessa cidade. Muda-se a própria concepção de urbano, que se atrela aos movimentos de comunicação, à economia internacionalizada, palcos que se comunicam entre si - o que leva a redesenhar-se o estudo das culturas urbanas, em que se leva em conta não só a definição sociodemográfica e espacial da cidade, mas a definição sociocomunicacional (2011, p. 20).

O desejo de Gato Preto é demonstrar que a Bahia tem outra face, distante da imagem da Bahia cantada em versos por seus filhos mais ilustres. Sa-

1 Gato Preto nasceu em Ilhéus, Bahia, pertence ao grupo GOG, de rap, e ao grupo Extremamente, de cordel urbano. 
be-se que a cidade possui uma imagem pública que se forma a partir da sobreposição das imagens criadas por vários indivíduos, sendo que cada um tem uma imagem própria e única da cidade. Para Bradbury e McFarlane (1989, p.76), "A grande cidade exerce sobre o homem um poder de atração e repulsão que tem servido freqüentemente de tema para a literatura”. Este olhar literário vai desconstruir o espaço urbano, para concebê-lo de maneira própria e particularizada, ordenando-o, limitando-o ou expandindo-o, para então reconstruí-lo como imagem por meio da linguagem. Dessa forma, o projeto do escritor é desnudar a existência de graves mazelas sociais e revelar faces de uma urbanização real, mesmo que cheia de contradições: "Olha só a ilusão daquele bobo/ Pensa que aqui é só mulher, samba e água de coco/ Acredita no que tevê passa, deve ta louco/ Ele não sabe que a maioria aqui passa sufoco" (GATO PRETO, 2005, p. 53).

O autor de "A Bahia que Caetano e Gil não cantaram" demonstra que a literatura está perto da realidade, pois se nutre dela. Desse modo, o relato do escritor fornece um depoimento da realidade contemporânea, do prisma de quem faz a história. A História, que é a síntese dos relatos de histórias, sejam elas "oficiais", sejam elas "paralelas". O texto, sem dúvida, oferece uma contribuição literária para a compreensão da subjetividade e da condição histórica contemporânea, demonstrando a quebra de diversos paradigmas e desnudando a idealização de diversos segmentos: “A intenção é mostrar a verdadeira cara da minha terra, sem inverdades, maquiagens, cenas de novela" (GATO PRETO, 2005, p. 55).

\section{Conclusão}

O espaço urbano não é somente o local em que ocasionalmente nos encontramos, mas a imagem mental que cada um faz do espaço da vida e que, dado o mesmo fundo de experiência, é a mesma para todos os indivíduos do mesmo grupo, com exceção de pequenas diferenças específicas: "O meio social que amolda o artista não só se inscreve na sua obra como também se insinua na inspiração que brota nele sob forma exterior. Esta forma, de certa maneira, ele também pode inventar" (BASTIDE, 1971, p. 73).

Logo, pode-se admitir que as imagens da cidade, consideradas aqui como as formas que servirão de suporte à representação, que emanam da obra de arte em geral, e da literatura em particular, reduzem-se a uma espécie de presença do todo circundante. E o escritor, por conseguinte, será aquele que executará o seu fazer, utilizando-se da língua e da linguagem, como litera- 
tura, remetendo sua cosmovisão para realidades ficcional e discursivo-literárias, que se articulam pela realidade vivenciada.

Pode-se dizer que o discurso literário comporta, também, a preocupação com a verossimilhança. A ficção não seria, pois, o avesso do real, mas outra forma de captá-lo, em que os limites de criação e fantasia são mais amplos que aqueles permitidos ao historiador.

É este, ao que parece, o verdadeiro papel social da literatura: agir por vias sinuosas. O discurso ficcional seria uma quase história, não precisa comprovar nada ou se submeter a testes, mas guarda preocupações com certa refiguração temporal, partilhada com a história.

Se o artista se deixa levar pela imaginação a uma dupla realidade ou se, como ocorre na contemporaneidade, ele evidencia a realidade de modo ideal, ou hostil, ou até mesmo fantástico, é porque, de fato, essa realidade se lhe apresenta dessa forma. Se a obra de arte literária espelha o mundo, se este mundo manifesta-se adverso do ideal, agressivo, descomposto, fracionado ou corrompido, ela apenas cumpre o seu papel de denunciar a situação em vigor e, quiçá indiretamente, poderá contribuir para uma possível transformação das circunstâncias.

A experiência urbana e a cena escrita estão, ambas, inseridas no mundo dos signos. Consequentemente, pode-se afirmar que a cidade tem a capacidade de produzir significados. Intrinsecamente ligado à modernidade, $\mathrm{o}$ universo urbano passa por transformações profundas e diversificadas que lhe alteram o perfil e a própria vida de seus habitantes: experiências e sonhos, necessidades e temores. Tudo ambiguamente novo. Tudo em permanente mudança, a alterar não apenas o cenário, mas a própria construção do imaginário da cidade.

$\mathrm{O}$ texto analisado apresenta, como personagem maior, a cidade. $\mathrm{O}$ autor alude a uma marginalidade de massa, não assinada, não legível, mas simbolizada. Imagens de uma "maioria silenciosa", que rumoreja a linguagem, na prática da ocupação e da inserção desorganizadas em um espaço que se pretende hierárquico e organizado.

Nesse texto de imagens difusas, a cidade torna-se opaca, uma paisagem nada paradisíaca, demonstram-se práticas e táticas cotidianas que circunscrevem o desenho da cidade da exclusão, mas, ainda assim, poética. Desse modo, é o texto de Gato Preto, em que o olhar agudo do autor sobre a metrópole acaba por revelar uma outra etnografia, cuja identidade do espaço desagrega. $\mathrm{O}$ autor vasculha o lado obscuro criado por uma supermoder- 
nidade (AUGÉ, 1994), produtora de não lugares ou de lugares não antropológicos. Constrói-se a geografia de um itinerário periférico da cidade, onde personagens se movem em um tempo presente, negando a paisagem idílica de um locus dissolvido pela violência, pela pobreza e pela exclusão.

\section{Referências Bibliográficas}

AUGÉ, Marc. Não lugares: introdução a uma antropologia da supermodernidade. Campinas: Papirus, 1994.

BASTIDE, Roger. Arte e Sociedade. 2. ed. São Paulo: Cia Editora Nacional, 1971.

BRADBURY, Malcolm; McFARLANE, James. Modernismo: guia geral (1890 - 1930). Trad.Denise Bottman. São Paulo: Companhia das Letras, 1989.

CHARTIER, Roger. História Cultural, entre práticas e representações. Lisboa: ifel, 1990.

FERRÉZ [Reginaldo Ferreira da Silva] (Org.). Literatura Marginal: talentos da escrita periférica. Rio de Janeiro: Agir , 2005.

GATO PRETO. A Bahia que Caetano e Gil não cantaram. In: FERRÉZ [Reginaldo Ferreira da Silva] (Org.). Literatura Marginal: talentos da escrita periférica. Rio de Janeiro: Agir, 2005. p. 51-55.

GOMES, Renato. A cidade, a literatura e os estudos culturais: do tema ao problema. Ipotesi: revista de estudos literários, Juiz de Fora, v. 3, n. 2, p. 19 - 30. Disponível em: <http://www.uff.br/revistaipotesi/files/2009/12/A-CIDADE-A-LITERATURA-E-OS-ESTUDOS1.pdf>. Acesso em: 17 mar. 2011.

MANNHEIM, Karl. Sociologia. São Paulo: Ática, 1982.

ORLANDI, E. Puccinelli. Interpretação: autoria, leitura e efeitos do trabalho simbólico. Campinas: Pontes, 2004.

PESAVENTO, Sandra Jatahy. O Imaginário da Cidade: Visões Literárias do Urbano - Paris, Rio de Janeiro, Porto Alegre. 2. ed. Porto Alegre: Editora da Universidade/UFRGS, 2002.

RAMA, Ángel. A cidade das letras. São Paulo: Brasiliense, 1985. 